\title{
Comment on: Incidence and Risk of Hypertension with Ramucirumab in Cancer Patients: A Meta-Analysis of Published Studies
}

\author{
Andreas Sashegyi $^{1} \cdot$ Yong Lin $^{1} \cdot$ David Ferry $^{1} \cdot$ Allen Melemed $^{1}$
}

Published online: 25 April 2015

(c) The Author(s) 2015. This article is published with open access at Springerlink.com

A meta-analysis by Wang et al. [1] assessing hypertension risk with ramucirumab use in patients with cancer was recently published in Clinical Drug Investigation. The authors concluded that ramucirumab treatment was associated with a significant increase in hypertension risk in cancer patients, and warned that treatment efficacy may be reduced due to the need to manage hypertension.

We acknowledge hypertension as an adverse reaction for ramucirumab. This is highlighted in the compound's package insert. However, the presentation by Wang et al. of the clinical severity of these events is misleading.

An analysis of pooled data was performed across six Phase III trials (ramucirumab $N=2748$, placebo $N=2248)$. In this analysis, $21.3 \%(n=585)$ of patients taking ramucirumab experienced hypertension of any grade during treatment, versus $7.4 \%(n=167)$ for patients taking placebo. This translates to an increase of $13.9 \%$ in the number of patients developing any grade hypertension, or about 1 in 7 . More severe hypertension ( $\geq$ Grade 3 ) was seen in $9 \%(n=246)$ of patients taking ramucirumab, and $2.5 \%(n=57)$ of patients taking placebo, a $6.5 \%$ increase, or approximately 1 in 15 patients. These percentages coincide relatively well with the data stated in the Wang et al. meta-analysis. However, of those patients experiencing hypertension, only eight cases $(<2 \%)$ led to

This comment refers to the article available at doi:10.1007/s40261015-0272-z.

Yong Lin

lin_yong@lilly.com

1 Eli Lilly and Company, Indianapolis, IN, USA discontinuation of any study treatment, showing that the hypertension was manageable.

These additional data suggest that although hypertension is a recognized adverse event in ramucirumab clinical trials, it was manageable and resulted in low rates of discontinuation across six multinational clinical phase 3 trials. Therefore, the suggestion by Wang et al. that hypertension can have an effect on treatment efficacy is unsupported by data.

Acknowledgments Writing support was provided by Eli Lilly and Company. A.S., Y.L., D.F. and A.M. are employees of Eli Lilly and Company and hold stocks.

Open Access This article is distributed under the terms of the Creative Commons Attribution-NonCommercial 4.0 International License (http://creativecommons.org/licenses/by-nc/4.0/), which permits any noncommercial use, distribution, and reproduction in any medium, provided you give appropriate credit to the original author(s) and the source, provide a link to the Creative Commons license, and indicate if changes were made.

\section{Reference}

1. Wang J, Wang Z, Zhao Y. Incidence and risk of hypertension with ramucirumab in cancer patients: a meta-analysis of published studies. Clin Drug Investig. 2015;35:221-8. 